Journal of Economics and Behavioral Studies

Vol. 4, No. 2, pp. 108-120, Feb 2012 (ISSN: 2220-6140)

\title{
Determining Growth Saturation Point for Sustainable Development
}

\author{
Mashhud Adenrele Fashola \\ University of Lagos, Lagos, Nigeria \\ maafashola@yahoo.com
}

\begin{abstract}
As economic growth may reach a point where further socio-economic development is not sustainable due to continual environmental degradation having negative development impact, the paper proposes a methodology for determining global central tendency for the saturation point of economic growth in its impact on sustainable development. The theoretical framework adopts a modified classical growth model, where economic growth is considered a means towards development, just as capital stock constitutes a means towards economic growth. In such a model, the impact of economic growth on sustainable development exhibits diminishing "marginal social productivity", until development reaches a stationary state, where the impact of growth reaches its climax and any further growth will bring a decline on the level of development. Economic growth is measured by per capita income while selected development indicators measure development. The factors responsible for the diminishing "marginal social productivity" of economic growth are population growth and depreciation rates of capital stock and physical environment. For empirical investigation, econometric studies explored the dependence of various development indicators on per capita income (US\$ PPP) for 99 countries, with a-priori expectation that the development indicators will progress with economic growth at a decreasing rate and reach saturation point. The results revealed that the saturation point or ultimate level of sustainable development is attained at per capita income of $\$ 36,400 \pm 500(P P P)$, a level exceeded by 13 percent of the countries. Results also showed that environmental degradation is both a causal factor and consequence of contemporary growth.
\end{abstract}

Keywords: Economic Growth; Sustainable Development; Development Indicators; Industrial Policies

\section{Introduction}

Socio-economic development requires economic growth while the adverse cumulative effect of continual economic growth on the environment may get to a critical point with severe consequences to the wellbeing of the people and the sustainability of development, it will be helpful to development policy to investigate the point at which economic growth as a means towards development reaches the limit of its capacity of impact on development. We may refer to such a point as the economic growth saturation point in its impact on development. Sustainable development has popularly been defined as one that "meets the needs of the present without compromising the ability of future generations to meet their own needs" (U.N. 1987). This definition suffices as a guide to the concept but is not measurable for precise policy purposes. The concept of sustainable development adopted here is an empirical one, which is currently defined by the point at which economic growth can no longer contribute to socio-economic development. In other words, this concept refers to an environmental "steady state" for the economy, where the state of the environment will not degenerate beyond the tolerable mean global standards. This approach is similar Silver's (1976) position of an economy in equilibrium with "basic ecological support systems" and that of Daly's $(1973,1991)$ steady state. The difference in our concept is that the "basic ecological support systems" are reflected indirectly, from time to time, by the saturation point of economic growth in its impact on socio-economic development as defined by the selected basic and composite development indicators. That saturation point of economic growth defines our environmental steady or stationary state. Since the objective of economic growth is socioeconomic development, economic growth should not be pursued after it has reached a point of futility in this respect while it continues to cause environmental degradation.

Our theoretical framework for determining the saturation point is similar to a classical growth process that leads to a stationary state defined by the point where economic growth characterized by diminishing net 
marginal social benefit reaches a point where its marginal net social benefit becomes zero. Net social benefit takes into account the social benefits and costs of economic, social, and environmental (including ecological) impacts of growth. For empirical analysis, various generally accepted development indicators will measure "development" as the dependent variable while per capita GNP will measure "economic growth" as the explanatory variable. The marginal net social benefit of growth becomes zero when, empirically, economic growth reaches a saturation point where it ceases to have any positive impact on development indicators. Economic growth from that point enhances only income and not development, the benefit of the rising income being more than offset by the cost of social and environmental degeneration. A similar idea to our growth saturation point put forward by Meadows et al $(1972,2004)$ is the "limits to growth", but their approach is quite direct, fairly comprehensive and complex in the sense that five activities were explored in respect of their individual and integrated impacts on the environment. The five activities are the food system, industrial system, population system, non-renewable resources system, and pollution system. "Progress" in the systems leads ultimately to a situation where the carrying capacities of the environment can no longer support further progress, and hence impose the limits to growth. Our position by contrast is simple and straightforward in the sense that we attempt to investigate the limits to the effectiveness of growth in promoting socio-economic development in a global country cross-section study.

This position is consistent with the Sen's (1985) functionality of income as applicable to individual nations and at various levels of economic growth. The UNDP concept of development is also consistent with this approach as is contained in Human Development Report 2002 (p.13), which states that: "Human development is about people, about expanding their choices to lead lives they value. (But) economic growth, increased international trade and investment, technological advance ... are means, not ends." Similarly, development economists, led by Seers (1969), Goulet (1971), Sen (1985, 1999), and Todaro and Smith (2009), are agreed that the concept of development is a multidimensional process that goes beyond economic growth and involves the entire social system, but where economic growth constitute the necessary condition for development. In section two, we present the modified neo-classical model for analyzing and determining growth stationary state, or saturation point, with respect to sustainable development. In section three, we carry out empirical analysis of the relationships between growth, development indicators and environmental depreciation utilizing data for 99 countries. Section 4 is the summary and policy conclusion.

\section{Theoretical Framework for Determining Saturation Point}

The theoretical framework is a modification of the neo-classical model of growth to determine the stationary state, or saturation point, for sustainable development. The basic endogenous growth model (Aghion and Howitt, 1998; Solow, 1957, 1993) may be presented as follows:

$$
\begin{gathered}
y=f(k) ; f(0)=0 ; f^{\prime}>0 ; f^{\prime \prime}<0 . \\
d k / d t=\bar{s} y-\delta k
\end{gathered}
$$

$y=Y / L$ is output $Y$ per Labour input $L$,

$k=K / L$ is capital stock $K$ per labour input,

$\bar{s}$ is savings ratio of income and

$\delta$ is depreciation rate.

It is to be noted, assuming constant $\mathrm{L}$, that

$$
d k / d t=d(K / L) / d t=(1 / L)(d K / d t)=(1 / L)(s Y-\delta K)=\bar{s} y-\delta k .
$$

The stationary state occurs when equation (2) becomes zero or $\bar{s} y=\delta k$. The stationary state occurs because output per capita (y) grows at a decreasing rate with respect to $k$ according to the attributes of equation (1), while depreciation rate grows at a constant proportion of $k$. Since savings rate is a constant proportion of $y$, which grows at a decreasing rate of $k$, depreciation or replacement investment catches up with gross investment or savings. At that point, capital stock per labour input (being net investment per labour input) stops growing and output per labour input also stops growing. This is illustrated in Fig. 1 where the stationary state occurs at $k=k_{3}$ and $y=f\left(k_{3}\right)$ and $d k / d t=0$. By modifying equation (2), the model can be extended to admit growing labour force (growing population), introduce foreign capital inflow to augment 
domestic savings, and environmental deterioration (or 'depreciation') as a consequence of growing industrial activities. Therefore, we have the extended model given as follows:

$$
\begin{aligned}
& y=f(k) ; f(0)=0 ; f^{\prime}>0 ; f^{\prime \prime}<0 . \\
& d k / d t=(\bar{s}+f) y-(\delta+n+\bar{\varepsilon}) k
\end{aligned}
$$

The parameters $\bar{s}$ and $f$ denote savings and foreign capital inflow ratios of income, while the parameters $\delta, n$, and $\bar{\varepsilon}$ refer respectively to depreciation rate of capital stock, labour force growth rate leading to the capital stock thinning, and rate of environmental deterioration as a consequence of growing industrial output and population. ${ }^{1}$ Net investment $d k / d t$ takes into account the social cost of growth by deducting the cost of environmental deterioration $\bar{\varepsilon} k$ in addition to the conventional depreciation of capital $\delta k$ and capital thinning of labour input growth $n k$. It is to be noted that the bar on the parameter $\bar{s}$ is an indication that savings ratio is a policy parameter in our model in the sense that government can influence savings ratio though fiscal and monetary policies and incentive schemes. Similarly, the bar on the rate of environmental deterioration $\bar{\varepsilon}$ taken as a proportion of capital stock is a policy parameter in the sense that government can influence the types of investment to be allowed in a region based on its environmental impact; investments with substantial adverse impact may be disallowed outright. It also implies that environmental deterioration can be reversed at a given additional cost to the investment outlay similar to the provision for capital stock depreciation.

Charging investors for environmental degradation or damage will reduce the rate of return on investment and hence restrict economic growth for a given technology and geographical space.

The stationary state occurs when equation (2') becomes zero, that is:

$$
(\bar{s}+f) y=(\delta+n+\bar{\varepsilon}) k \quad \text { alternatively } \quad \bar{s} y=(\delta+n+\bar{\varepsilon}) k \text {, where } f=0 .
$$

During the process of economic growth, savings utilized for gross investment will initially exceed depreciation to produce a positive net investment. On account of diminishing returns to net investment per labour, i.e. $f^{\prime \prime}(k)<0$, savings function of income, $\bar{s} y=\bar{s} f(k)$, will exhibit the same attribute as equation (1), that is, $\bar{s} f^{\prime \prime}(k)<0$, while the depreciation of capital stock, environmental deterioration, and capital thinning are linear functions of $k$. The resultant stationary state is also illustrated in fig. 1 for expanding labour force and foreign capital inflow.

There is a greater limit $k_{1}$ to economic growth given by $y_{1}=f\left(k_{1}\right)$ when the consequent environmental deterioration is taken into account than when it is not. The environmental limit to economic growth can be relaxed to $y_{2}=f\left(k_{2}\right)$ when foreign capital inflow is allowed as this will allow greater investment ratio of income that can compensate more for environmental deterioration. Without taking environmental deterioration into account, growth will exceed the safe bounds of the environment as the stationary state is extended to $f\left(k_{3}\right)$. alternatively, $f\left(k_{4}\right)$ with foreign capital inflow. The implication of the model is that sustainable development defined by the investment equation (2') will accompany economic growth up to the stationary state $f\left(k_{1}\right)$ or $f\left(k_{2}\right)$ if domestic resources are augmented by costless foreign capital inflow. Such capital inflow may be used to remedy environmental degradation to extend the frontier of socioeconomic development by permitting further output expansion that will be favorable to a higher state of sustainable development. The foreign aid or capital inflow can also be used to give incentives to investors to move to sparsely populated regions where the environment can accommodate growth without jeopardy to the environment and ecological balance. The same effect is achievable through government policy that may raise

${ }^{1}$ If labour $L$ grows at the rate $n$, and noting that $k=K / L$ and $\mathrm{dK} / \mathrm{dt}=\mathrm{sY}-\delta \mathrm{K}$, then $\mathrm{dk} / \mathrm{dt}$ becomes:

$$
\frac{L(d K / d t)-K(d L / d t)}{L^{2}}=\frac{1}{L} d K / d t-\frac{K}{L}\left(\frac{d L / d t}{L}\right)=\frac{1}{L}(s Y-\delta K)-k n=s y-\delta k-n k .
$$


national savings ratio towards government investment to compensate for environmental damage. The model also implies that unrestricted growth that attains the higher stationary states of $f\left(k_{3}\right)$ or $f\left(k_{4}\right)$ is tantamount to retrogression as regards sustainable development objectives since environmental degradation has not been taken into account.

\section{Fig. 1: Growth Model Stationary States}

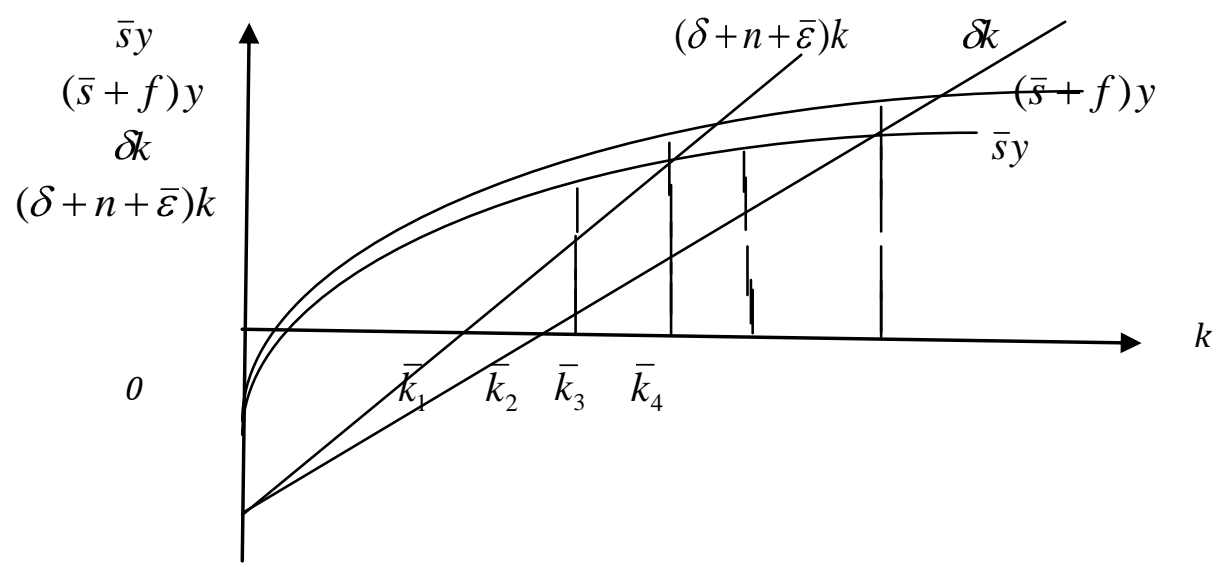

$\bar{k}_{1}$ : When environmental deterioration is taken into account without foreign capital inflow.

$\bar{k}_{2}$ : When environmental deterioration is taken into account with foreign capital inflow.

$\bar{k}_{3}$ : When environmental deterioration is disregarded without foreign capital inflow.

$\bar{k}_{4}$ : When environmental deterioration is disregarded with foreign capital inflow.

The modified model has not taken technical progress into account as in Solow-Swan model. This will be in order if we assume that environmental sustainability of development assumes a given geographical space and a given technology. A given technology may be assumed because it may be difficult in the medium term to offset the constraints and limits imposed by the environment and ecological balance, as with growing carbon dioxide emission and global climate change and its adverse consequences for human development and biodiversity conservation. The growth saturation point may in this wise be taken as dynamic and not static.

\section{Empirical Analysis}

From development literature and our theoretical framework, we can postulate that:

- Economic growth is necessary for socioeconomic development;

- With continual economic growth leading to diminishing marginal net social benefit on account of environmental constraints, population (and labour force) growth with consequent thinning of physical capital and infrastructure, socio-economic development reaches a stationary state or saturation point, ceteris paribus, (as illustrated in figure 1).

- International development cooperation and assistance, through the preservation and reversal of degradation of the environment, may however promote sustainable development beyond regional or national limitations and environmental constraints, as is depicted by parameter $f$ in equation (2) representing foreign capital inflow to supplement domestic investment resources and development assistance towards environmental beautification, preservation, purification, and reversal of degradation.

Model specifications attempt to take these propositions into account. Basically, economic growth is the explanatory variable while sustainable development is the dependent variable. Several development indicators are explored as measures of sustainable development. This theoretical framework appears to have 
empirical support from some past studies that attempt to explore the relationship between "happiness" and economic growth. One of such studies is by Layard (2005), who explored the relationship between income and "happiness", suggesting that beyond per capita GNP of $\$ 22,500$, there is no significant difference in the levels of happiness and satisfaction among the people of the countries. However, such studies define happiness subjectively. This study attempts to explore the relationship between development, economic growth, and environmental degradation, where various generally accepted development indicators objectively measure development. Specifically, we intend to establish empirically the level of per capita income beyond which there occurs no significant improvement on socio-economic development while the environment continues to suffer degradation. Development in this context takes into account all relevant and measurable aspects of social concerns including income, education, sound health and longevity, income distribution and poverty, security, and most importantly environmental protection for long-term sustainability of development, among others.

Articulation of the dependent and explanatory variables: For the measurement of economic growth, we employ gross national income (GNI) per capita (in terms of 2005 US\$ at purchasing power parity, PPP). For the measurement of environmental degradation, we explore three representative indicators for which data are generally available namely: carbon dioxide emission per capita, carbon dioxide emission per square kilometer, and population density. As for dependent variables to measure socioeconomic development, we require a set of veritable development indicators. One composite indicator that is explored here is the UNDP's Human Development index ( $H D I)$. The other ones explored comprise more comprehensive set of indicators than HDI in order to have a wider coverage of millennium development goals and major national development objectives of life sustenance, equitable income distribution and social justice, self-reliance, environmental protection and preservation, and balanced development.

Below is the list and description of the basic and composite indicators, in addition to HDI:

- Percentage of Household with Access safe Water (HAW): Household access to safe water reflects environmental sustainability of development and life sustenance.

- Percentage of Population living below Poverty Line of $\$ 1.25$ a day (PPL): This indicator reflects income distribution and level of poverty, which affects well being and happiness. Percentage of population living below $\$ 1.25$ a day can be drastically reduced with significant reduction in income inequality.

- Population density (POPD): Population density is obviously expected to affect environmental sustainability.

- Carbon dioxide emission per capita (CDE): Carbon dioxide emission per capita may be used as a measure of the extent of environmental pollution. Alternatively, depending on econometric tests, carbon dioxide emission per square kilometer of land space may be adopted as a measure of environmental pollution.

- LECI: Normalised average of Life Expectancy and Child "Immortality": Life expectancy is considered a good indicator of life sustenance but child mortality reflects life sustenance, level of poverty, and income inequality much better. This is because child mortality is much more sensitive to life sustenance in respect of adequacy of food and nutrition, housing, access to safe water, diseases, health care, and female education. Child "immortality" or survival rate per thousand is the complement of child mortality and is here measured by 1000 minus Child Mortality (CM) per thousand. We normalize the composite index by dividing Life Expectancy $(L E)$ by 82 years (being the current highest life expectancy), dividing child "immortality" by 1000 (the highest possible), adding both figures and taking the percentage simple average. That is:

- $\quad$ LECI $=[100(\mathrm{LE} / 82)+100(1000-\mathrm{CM}) / 1000] / 2<100$

- PAHAFN: Composite indicator of the Percentage living Above poverty line, percentage household Having Access to water, and percentage of the people Fully Nourished. Percentage living above poverty line equals 100 minus percentage living below poverty line while the fully nourished equals 100 minus percentage undernourished. 
The basic indicator of the explanatory variable, $X$, is GNI per capita. Other indicators of economic growth are carbon dioxide emission per capita and population density, given the presumption that carbon dioxide emission and population density are substantially correlated with economic growth on account of its impact on the environment and attraction of migration.

Specification of the Regression Equations: The regression function relating $Y$ (measuring development) to $X$ (measuring economic growth) corresponding to equation (1) of the theoretical framework, is given as:

$$
Y=f(X)+\mu ; \quad f(0)=0, f^{\prime}>0, f^{\prime \prime}<0 ; \quad(\mu \text { being the error term }) .
$$

Two explicit specifications consistent with implicit function (1') are given by the quadratic and power functions as follows:

$$
\begin{aligned}
& \text { Quadratic specification: } Y=a+b X-c X^{2}+\mu ; \\
& \text { Power or log Function: } \quad Y=a X^{b} e^{\mu} ; \quad \text { or } \log _{e} Y=a^{\prime}+b \log _{e} X+\mu ; a^{\prime}=\log _{e} a \text {. (5) }
\end{aligned}
$$

The quadratic specification (4) has the maximum or saturation point for sustainable development where $d Y / d X=0$ and $\mathrm{X}=\mathrm{b} / 2 \mathrm{c}$ from where development becomes unsustainable and decline sets in with further economic growth. However, for the power, function (5) turning point does not exist and hence there is no point of decline as sustainable development approaches saturation point asymptotically. Nevertheless, the saturation point may be defined as the point from where $d Y / d X$ is sufficiently close to zero; that is, where $d Y / d X=a b / X^{1-b}$ becomes zero approximately to a given number of decimal places. If we still desire a definite turning point for the power function (5) to determine the saturation point for sustainable development, we can achieve this by subtracting a linear function from (5). Thus, we can specify $Y$ as:

$$
\begin{aligned}
& \qquad Y=a X^{b} e^{\mu_{1}}-c X+\mu_{2} ; a>0 ; c>0 ; 0<b<1 ; E\left(\mu_{1}\right)=E\left(\mu_{2}\right)=0 . \\
& \text { Equation (6) has a saturation point where } \frac{d Y}{d X}=0 \text { and } X=\left(\frac{a b}{c}\right)^{\frac{1}{1-b}} .
\end{aligned}
$$

Equation (6) can be estimated in that form using E-Views econometric package. Equations (4), (5) or (6) are capable of determining for us the GNI per capita corresponding to the ultimate sustainable development at the stationary state. It can similarly determine for us the corresponding levels of carbon dioxide emission and population density consistent with ultimate sustainable development. In addition, simple regression analyses are carried out to investigate the dependence of carbon dioxide emission on GNI per capita, and vice versa. The basis of this is that as economic growth proceeds, energy consumption increases and will be reflected among others in carbon dioxide emission. On the other hand, the more the energy a nation consumes, the more are the economic activities and growth that take place. Granger causality tests between indicators of environmental pollution and economic growth are also carried out to explore the extent of mutual dependence and causal dominance.

Data Sources and Sample Size: Data used for the empirical analysis in respect of Human Development Index, Gross National Income per capita (US\$ 2005, PPP), Life Expectancy, Child Mortality, Percentage of population below Poverty Line of US\$1.25, Percentage of Household with Access to Safe Water, Percentage of population that are under-nourished are sourced from UNDP and World Bank statistical publications. Carbon dioxide emissions are obtained from data collected in year 2008 by Carbon Dioxide Information Analysis Centre (CDIA) for United Nations and are obtainable from Wikipedia. Population figures that are obtained from United Nations publications refer to year 2009, 2010 or 2011. Land area data are obtained from CIA World Fact book. The sample of 99 countries was selected based on data availability and excluding countries with very small population. Ninety percent of the countries have population of five million and above, while the remaining 10 percent have populations above 2.7 million. Appendix A contains all the data.

\section{Results}

Equations (4), (5), and (6) were estimated for each of the nine dependent variables. The saturation points for equation (4) and (6) where $\mathrm{dY} / \mathrm{dX}=0$, which we interpret as stationary states for sustainable development are given respectively as: 
1. $X^{*}=b / 2 c$

2. $X^{*}=\left(\frac{a b}{c}\right)^{\frac{1}{1-b}}$

Where $\mathrm{X}^{*}$ is the limit of acceptable GNI per capita (PPP) for the ultimate sustainable level of development, that will determine the level of growth restrictions. $X *$ may also refer to acceptable limit of carbon dioxide emission per capita and population density. A turning point does not exist for equation (5) as pointed out earlier; so the saturation point may be taken as the point from where $d Y / d X=a b / X^{1-b}$ becomes zero approximately to a given number of decimal places. The value of $X$ at that point gives the limit of acceptable economic growth, carbon dioxide emission per capita, and population density, whichever is applicable. The acceptable limits of GNI per capita, carbon dioxide emission per capita, and population density may vary for different development indicators. Only the significant equations are presented and discussed below.

First, to be considered is the estimated equation (4), concerning the saturation point of sustainable development with respect to economic growth, where GNI per capita is the explanatory variable and HDI is the dependent variable to measure sustainable development:
$H D I=40.575+1.6384(X)-0.01304\left(X^{2}\right)$
t-statistic: (29.237) (16.639)
$(-11.042)$
(4.1)
$\mathrm{N}=99 ; \quad \mathrm{R}^{2}=0.843 ; \mathrm{DW}=1.678$;

Where HDI is human development, index (multiplied by 100) and $X$ is gross national income per capita normalised (as percentage of the highest GNI per capita). Norway has US\$58,800 (2005 US\$ PPP) GNI per capita for year 2010; that is Norway's GNI per capita is 100. From the regression equation above, saturation point occurs at $X^{*}=b / 2 c=62.82$, where $\mathrm{b}=1.6384, \mathrm{c}=0.01304$. This means that economic growth based on HDI development indicator should be restricted to a maximum of US\$36,900 corresponding to $62.82 \%$ of the current highest GNI per capita. Economic growth in excess of US\$36,900 is not desirable as it cannot raise the level of socio-economic development and yet it worsens environmental degradation. Growth beyond such a threshold definitely has negative marginal social net benefit because it further damages the environment with no marginal contribution to development.

Employing the alternative regression equation (5) $\left\{Y=a X^{b}\right\}$ and (6) $\left\{Y=a X^{b}-c X\right\}$, we have the following estimated equations respectively:

$$
\begin{aligned}
Y & =36.1075 X^{0.21704} \\
\mathrm{R}^{2} & =0.8968 ; \mathrm{t}(1)=34.709 ; \mathrm{t}(2)=25.762 ; \mathrm{DW}=1.901 \\
Y & =31.2099 X^{0.34109}-0.6519 X \\
\mathrm{R}^{2} & =0.9386 ; \quad \mathrm{t}(1)=33.872 ; \mathrm{t}(2)=19.351 ; \mathrm{t}(3)=-6.5335 ; \mathrm{DW}=2.0154
\end{aligned}
$$

$Y$ Represents HDI; $X$ represents GNI per capita; $\mathrm{t}(i)$ is t-statistic for regression coefficient $i$.

For equation (5.1), saturation point occurs where $d Y / d X=a b / X^{1-b} \rightarrow 0$ or approximates zero to a relevant decimal place value, for a sufficiently large value of $X$. For equation (6.1), the saturation point occurs at the turning point where

$$
d Y / d X=a b / X^{1-b}-c=0 \text {, the solution of which gives } X^{*}=(a b / c)^{1 /(1-b)} .
$$

With $\mathrm{a}=36.1075$ and $\mathrm{b}=0.21704$ for estimated equation (5.1), the saturation point occurs where $d Y / d X=a b / X^{1-b} \rightarrow 0 . d Y / d X$ becomes zero to the nearest whole number when the normalised GNI per capita $X=66$. In addition, this is equivalent to US\$39,400.

With $\mathrm{a}=31.2099, \mathrm{~b}=0.34109$, and $\mathrm{c}=0.6519$, for estimated equation (6.1), the turning point occurs where $X^{*}=(a b / c)^{1 /(1-b)}=\mathbf{6 9 . 2 3 5}$ which is equivalent to US\$40,780.

Interestingly, the threshold values for the ultimate level of sustainable development for all the various specifications are quite close, ranging from US\$37,000 to US\$41,000. We have so far used HDI as a measure of development. There are other measures of development that we need to explore in determining the ultimate 
level of sustainable development. Among such development indicators that we have discussed earlier are LECI (composite index of Life Expectancy and Child Immortality), PAP (\% Population $\underline{\text { Above }}$ Poverty line),

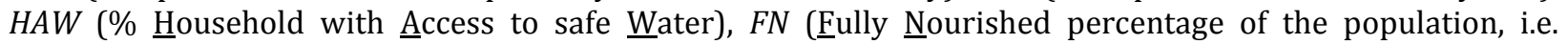
percentage not under-nourished), PAPFN (composite index of PAP and FN), HAWFN (composite index of HAW and FN), PAHAFN (composite index of PAP, HAW, and FN).

We have carried out regression analysis for all those indicators. However, we report below, respectively, only the regression results for LECI, HAWFN, and HAPAFN, being the most statistically significant:

$$
\begin{aligned}
& L E C I=79.683+0.6939(X)-0.00561\left(X^{2}\right) \\
& \text { t-Statistic: } \quad \text { (84.189) (10.448) }(-7.064) \mathrm{N}=97 ; \quad \mathrm{R}^{2}=0.676 ; \mathrm{DW}=1.777 \\
& \text { HAWFN }=68.925+1.0756(X)-0.0088\left(X^{2}\right) \\
& \text { t-Statistic: } \quad \text { (41.362) (9.1996) (-6.301) } \quad \mathrm{N}=97 ; \quad \mathrm{R}^{2}=0.611 ; \mathrm{DW}=1.924 \\
& \text { PAHAFN }=64.266+1.1097(X)-0.0089\left(X^{2}\right) \\
& \text { t-Statistic: } \quad \text { (39.437) (9.7056) (-6.513) } \quad \mathrm{N}=97 ; \quad \mathrm{R}^{2}=0.646 ; \mathrm{DW}=1.847
\end{aligned}
$$

where $L E C I$ is composite index of life expectancy and child immortality, HAWFN is composite index of household access to safe water and adequate food and nutrition, PAHAFN is composite index of the percentage of population living above poverty line, having access to safe water and not under-nourished, and $X$ is GNI per capita (normalised as percentage of the current highest value).

As earlier explained, saturation point occurs at $X^{*}=b / 2 c$ where $b$ is the regression coefficient for $X$ and $c$ is regression coefficient for $X^{2}$. On this basis, the saturation points for the respective development indicators as expressed in equations (4.2) to (4.4) are given as follows:

Table 1: Ultimate Development Saturation Points for Various Development Indicators

\begin{tabular}{llll}
\hline Equation & Development Indicator & $\begin{array}{l}\text { GNI per capita } \\
\text { (Normalised) }\end{array}$ & GNI per capita 2005 US\$ \\
\hline$(4.1)$ & HDI & 62.2 & US $\$ 36,900$ \\
$(4,2)$ & LECI & 61.8 & US $\$ 36,300$ \\
$(4.3)$ & HAWFN & 61.0 & US $\$ 35,900$ \\
$(4.4)$ & PAHAFN & 62.3 & US $\$ 36,600$ \\
& AVERAGE & 61.8 & US $\$ 36,400$ \\
& RANGE & $61.0-62.3$ & $\$ 36,400 \pm 500$ \\
\hline
\end{tabular}

It is clear that the various development indicators employed produced virtually the same level of ultimate sustainable development, around US $\$ 36,400$. This amount is equivalent to GNI per capita of $\$ 18,000$ to $\$ 24,000$ at the conventional exchange rate. We have observed that there is no positive correlation between HDI and GNI per capita for countries with GNI per capita of $\$ 25,000(P P P)$ and above. GNI per capita of $\$ 25,000 P P P$ is equivalent to between $\$ 12,500$ and $\$ 17,000$. Nations that have reached this level of development should be discouraged from promoting further economic expansion. Beyond such a level of growth and development, further economic growth would be adverse to development objectives as it would bring no gain to socioeconomic development but results in environmental depreciation or degradation, given the current state of technology. Technological progress may reduce the adverse environmental impact of economic activities, such as the development of solar and wind energy as opposed to the thermonuclear, the development of energy-saving equipment, and the recycling of waste or its conversion to energy.

We have in this regard carried out regression analysis to explore the impact of economic growth on the environment or vice versa. Using the carbon dioxide emission per capita $C D E$ as the dependent variable on GNI per capita, and vice versa, the following regressions are the best obtained among various specifications:

$C D E=1.3065+0.16845(X)$

t-statistic: $\quad(1.7203)$

(8.1774)

$\mathrm{N}=99 ; \quad \mathrm{R}^{2}=0.408$

DW $=1.917$ 


$$
\begin{aligned}
& X=36.1075 C D E^{0.21704} \\
& \mathrm{t}(1)=6.372 ; \quad \mathrm{t}(2)=8.126 ; \quad \mathrm{N}=99 ; \quad \mathrm{R}^{2}=0.5533 ; \quad \mathrm{DW}=1.776
\end{aligned}
$$

It is clear from estimated equation (4.5) that economic growth as indicated by GNI per capita has definite impact on the environment as indicated by CDE, although it only explained $41 \%$ of the variation in CDE. On the other hand, energy consumption as indicated by CDE is essential for economic growth as shown by estimated equation (5.2), explaining 55\% of growth in GNI per capita. We also carried out Granger causality test. Granger causality test indicates that the null hypothesis must be rejected in both cases. This implied that economic growth led to environmental depreciation, while carbon dioxide emission was necessary for economic growth; that is, environmental depreciation and economic growth were mutually dependent and significantly correlated. Therefore, the conclusion has to be drawn that economic growth having social cost in terms of environmental degradation needs to be restricted to the dynamic saturation point of sustainable development, where marginal social benefit of growth is nil.

\section{Summary and Conclusion}

Summary: The paper sets out to investigate the nature of the progressive impact of economic growth on socio-economic development, suspecting that economic growth will have a saturation point at which its marginal net social benefit decreases to zero level and development reaches the ultimate sustainable level. It is expected that socioeconomic development will not be sustainable beyond such a point, as further economic growth will inflict more environmental and social damage than the corresponding benefit. The paper adopts a methodology for determining global central tendency for the growth saturation point based on an extended classical growth model from which we derive the specification of functions for econometric analysis, estimation and interpretation. The model applies the classical concept of stationary state to the saturation point of sustainable development, while the capital stock depreciation is extended to include environmental depreciation in addition to the thinning of capital stock and infrastructural facilities occasioned by growing population and labour force.

The econometric studies explored the dependence of various development indicators (representing sustainable development) on per capita income (US\$ PPP) (representing economic growth) for 99 countries, with a-priori expectation that as economic growth proceeds, sustainable development will progress at a decreasing rate until it reaches saturation point. Development indicators adopted include: UNDP Human Development Index (HDI); composite indicators of life expectancy and child 'immortality'; composite indicators of percentages of population living above poverty line (of $\$ 1.25$ a day), population not undernourished, and population having access to safe water. We also explored the relationship between environmental depreciation and economic growth, employing carbon dioxide emission per capita for environmental depreciation and gross national income (GNI) per capita US\$ purchasing power parity (PPP) for economic growth indicator, testing for causality between the two variables. The results revealed that the saturation point of sustainable development is attained at per capita income of $\$ 36,400 \pm 500(P P P)$, a level exceeded by 13 percent of the countries. This level of per capita income at $P P P$ exchange rate is equivalent to per capita of income between $\$ 18,000$ and $\$ 24,000$ at the market exchange rate.

No positive correlation or causality was found between HDI and GNI per capita for countries with GNI per capita of $\$ 25,000(P P P)$ and above. Econometric analysis carried out to explore the impact of economic growth on the environment or vice versa showed that economic growth had definite adverse impact on the environment as indicated by carbon dioxide emission per capita, with Granger causality test revealing mutual causality of economic growth and carbon dioxide emission per capita. We did not find any significant correlation or causality between population density and economic growth. No significant correlation was also found between carbon dioxide emission per square kilometer and per capita income. Thus, the conclusion has to be drawn that economic growth having social cost in terms of environmental degradation needs to be restricted to the saturation point of sustainable development, where marginal net social benefit of growth is nil. Such saturation point is however subject to the state of technology and its application in a given country as well as her environmental management efficiency. 
Policy Conclusion: Having drawn the conclusion that economic growth ought to be restricted around the saturation point of sustainable development, especially to guard against environmental disutility, it will be useful to consider specific ways of restricting detrimental economic growth. Regions and urban centres that have attained per capita GNI of between $\$ 25,000$ and $\$ 36,000$ (PPP) should not permit expansion of industrial activities within the region. Further progress on well-being of the citizens may be achieved through more equitable income distribution and social justice or through more environmentally friendly selection or relocation of industrial activities. Any economic expansion in such a region may be permitted only if its activities cannot have any adverse effect on the physical, social, or economic environment. Otherwise, firms requiring expansion should be requested to move to regions or countries with lower per capita GNI and relatively low carbon dioxide emission per capita. International development cooperation and assistance can help in promoting cleaner environment by adopting agreements and incentive schemes for this purpose.

Nations that have reached the saturation point of sustainable development should encourage their investors to move to friendly countries with relatively low income and carbon dioxide emission per capita. There should be greater international cooperation to allow freer movement of capital and labour with a view to protecting the global environment. Nations pursuing nuclear energy programmes have generally reached the growth saturation point of sustainable development, and as such should be prevailed upon by the international community to halt forthwith all their nuclear energy programmes. Striving for further economic growth has been shown to be of no additional benefit to the wellbeing of the people. Industrially advanced nations should simply embark on research and development in respect of environmentally friendly economic activities that will replace those that are not as a way of expanding the frontiers of sustainable development.

\section{References}

Aghion, P. \& Howitt, P. (1998). Endogenous Growth Theory. Cambridge, Mass.: M.I.T.

Daly, H. E. (1973). Towards a Steady State Economy. San Francisco: Freeman

Daly, H. E. (1991). Steady State Economics, $2^{\text {nd }}$ ed. Washington DC: Island Press.

Goulet, D. (1971). The Cruel Choice: A New Concept in the Theory of Development. New York: Atheneum. Layard, R. (2005). Happiness: Lessons from a New Science; New York: Penguin.

Meadows, D. H., Meadows, D. L., Randers, J. \& Behrens, W. W. (1972). The Limits to Growth; New York: University Books.

Meadows, D. H., Randers, J. \& Meadows, L. (2004). The Limits to Growth: The 30-year update. Chelsea: Chelsea Green Publishing Co.

Todaro, M. P. \& Smith, S. C. (2009). Economic Development. 10

Seers, D. (1969): The Meaning of Development. Paper presented at the Eleventh World Conference of the Society for International Development. New Delhi.

Sen, A. (1985). Commodities and Capabilities. Amsterdam: Elsevier,.

Sen, A. (1999). Development as Freedom. New York: Knopf.

Silver, R. (1976). The Sustainable Society: Ethics and Economic Growth; Philadelphia: Westminster Press.

Solow, R. M. (1957). Technical Change and Aggregate Production Function. Review of Economics and Statistics, 39, 312-320.

Solow, R. M. (1993). Sustainability: An Economist's Perspective in R. Dorfman \& S. Dorfman, (eds.) (1993). Economics of the Environment: Selected Readings. $3^{\text {rd }}$ edn. New York: Norton.

UNDP (2002). Human Development Report: Deepening democracy in a fragmented world; New York: Oxford University Press.

World Bank (1991). World Development Report. New York: Oxford University Press. 


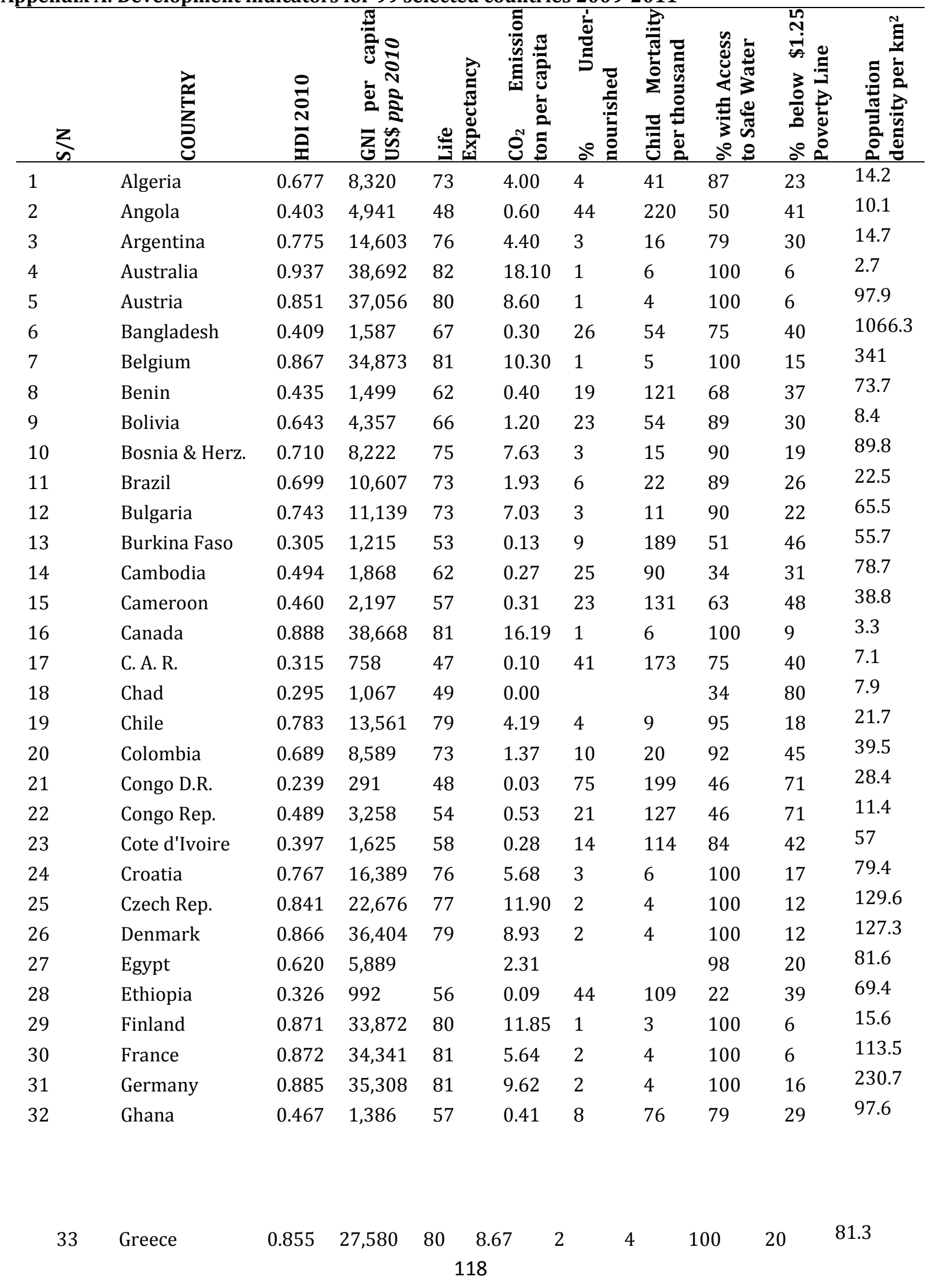




\begin{tabular}{|c|c|c|c|c|c|c|c|c|c|c|}
\hline 34 & Hong Kong & 0.862 & 45,090 & 83 & 5.63 & 2 & 4 & 100 & 10 & 93.94 \\
\hline 35 & Hungary & 0.805 & 17,472 & 74 & 5.60 & 3 & 7 & 99 & 14 & 106.8 \\
\hline 36 & India & 0.519 & 3,337 & 64 & 1.33 & 22 & 69 & 86 & 25 & 349.2 \\
\hline 37 & Indonesia & 0.600 & 3,957 & 71 & 1.67 & 16 & 41 & 78 & 13 & 123.7 \\
\hline 38 & Iran & 0.702 & 11,764 & 72 & 6.60 & 5 & 32 & 93 & 18 & 40 \\
\hline 39 & Ireland & 0.895 & 33,078 & 80 & 9.78 & 2 & 4 & 100 & 6 & 59.1 \\
\hline 40 & Israel & 0.872 & 27,831 & 82 & 8.70 & 3 & 5 & 100 & 24 & 342.4 \\
\hline 41 & Italy & 0.854 & 29,619 & 81 & 7.52 & 2 & 4 & 100 & 10 & 193 \\
\hline 42 & Jamaica & 0.688 & 7,209 & 72 & 5.19 & 5 & 31 & 93 & 15 & 258.9 \\
\hline 43 & Japan & 0.884 & 34,692 & 83 & 9.80 & 2 & 4 & 100 & 16 & 36.9 \\
\hline 44 & Jordan & 0.681 & 5,956 & 73 & 3.23 & 5 & 20 & 91 & 14 & 67.2 \\
\hline 45 & Kazakhstan & 0.714 & 10,234 & 68 & 13.76 & 5 & 30 & 86 & 8 & 5.6 \\
\hline 46 & Kenya & 0.470 & 1,628 & 55 & 0.28 & 30 & 128 & 62 & 50 & 65.1 \\
\hline 47 & Korea, Rep. & 0.877 & 29,518 & 80 & 10.27 & 3 & 5 & 92 & 15 & 499.9 \\
\hline 48 & Kuwait & 0.771 & 55,719 & 78 & 27.74 & 5 & 11 & 87 & 5 & 145.7 \\
\hline 49 & Libya & 0.755 & 17,068 & 75 & 8.77 & 5 & 17 & 72 & 7 & 3.5 \\
\hline 50 & Madagascar & 0.435 & 953 & 61 & 0.10 & 35 & 106 & 45 & 50 & 34.1 \\
\hline 51 & Malaysia & 0.744 & 13,927 & 75 & 7.03 & 3 & 6 & 95 & 5 & 76.6 \\
\hline 52 & Mali & 0.309 & 1,171 & 49 & 39.93 & 10 & 194 & 48 & 36 & 9.9 \\
\hline 53 & Mauritania & 0.433 & 2,118 & 57 & 0.59 & 18 & 1 & 56 & 40 & 3.3 \\
\hline 54 & Mexico & 0.750 & 13,971 & 75 & 4.19 & 10 & 17 & 91 & 18 & 55.7 \\
\hline 55 & Mongolia & 0.622 & 3,619 & 67 & 3.93 & 29 & 41 & 62 & 36 & 1.9 \\
\hline 56 & Morocco & 0.567 & 4,628 & 72 & 1.43 & 5 & 36 & 80 & 15 & 76.9 \\
\hline 57 & Mozambique & 0.284 & 854 & 48 & 0.13 & 31 & 130 & 42 & 70 & 26.6 \\
\hline 58 & Netherlands & 0.890 & 40,657 & 81 & 10.36 & 2 & 5 & 100 & 11 & 400.8 \\
\hline 59 & Newzealand & 0.907 & 25,437 & 80 & 7.50 & 3 & 6 & 100 & 6 & 15.5 \\
\hline 60 & Nicaragua & 0.565 & 2,567 & 73 & 0.86 & 5 & 27 & 81 & 48 & 44.7 \\
\hline 61 & Niger & 0.261 & 675 & 52 & 0.07 & 28 & 167 & 46 & 63 & 10.5 \\
\hline 62 & Nigeria & 0.423 & 2,156 & 48 & 0.60 & 8 & 186 & 60 & 70 & 149.7 \\
\hline 63 & Norway & 0.938 & 58,810 & 81 & 8.78 & 1 & 4 & 100 & 5 & 14.3 \\
\hline 64 & Pakistan & 0.490 & 2,678 & 67 & 0.89 & 23 & 89 & 90 & 24 & 208.7 \\
\hline 65 & Panama & 0.755 & 13,347 & 76 & 2.06 & 17 & 23 & 91 & 29 & 42.1 \\
\hline 66 & Paraguay & 0.640 & 4,585 & 72 & 0.62 & 4 & 28 & 83 & 19 & 16.8 \\
\hline 67 & Peru & 0.723 & 8,424 & 73 & 1.46 & 13 & 24 & 81 & 35 & 22.7 \\
\hline 68 & Phillipines & 0.638 & 4,002 & 72 & 0.76 & 12 & 32 & 85 & 33 & 308.9 \\
\hline 69 & Poland & 0.795 & 17,803 & 76 & 8.32 & 41 & 7 & 90 & 17 & 123.1 \\
\hline 70 & Portugal & 0.795 & 22,105 & 79 & 5.47 & 2 & 4 & 90 & 18 & 115.6 \\
\hline 71 & Romania & 0.767 & 12,844 & 73 & 4.37 & 5 & 14 & 57 & 25 & 93.7 \\
\hline 72 & Russian Fed. & 0.719 & 15,258 & 69 & 10.75 & 5 & 13 & 96 & 13 & 8.2 \\
\hline 73 & Saudi Arabia & 0.752 & 24,720 & 73 & 14.83 & 5 & 21 & 95 & 13 & 14.4 \\
\hline 74 & Senegal & 0.411 & 1,816 & 56 & 0.39 & 25 & 108 & 72 & 54 & 65.5 \\
\hline
\end{tabular}




\begin{tabular}{|c|c|c|c|c|c|c|c|c|c|c|}
\hline 75 & Singapore & 0.846 & 48,893 & 81 & 10.59 & 1 & 3 & 100 & 6 & 97.1 \\
\hline 76 & Slovakia Rep. & 0.818 & 21,658 & 75 & 6.85 & 3 & 8 & 90 & 21 & 111.7 \\
\hline 77 & South Africa & 0.597 & 9,812 & 52 & 8.84 & 5 & 67 & 87 & 50 & 35.9 \\
\hline 78 & Spain & 0.863 & 29,661 & 82 & 7.77 & 2 & 4 & 90 & 20 & 80.2 \\
\hline 79 & Sudan & 0.379 & 2,051 & 58 & 0.28 & 20 & 109 & 69 & 40 & 16 \\
\hline 80 & Sweden & 0.885 & 36,936 & 81 & 5.21 & 1 & 3 & 100 & 5 & 20.1 \\
\hline 81 & Switzerland & 0.874 & 39,849 & 82 & 4.87 & 2 & 5 & 100 & 7 & 183.6 \\
\hline 82 & Syria & 0.589 & 4,760 & 74 & 3.33 & 5 & 16 & 79 & 12 & 106.6 \\
\hline 83 & Tajikistan & 0.580 & 2,020 & 67 & 0.99 & 26 & 64 & 58 & 53 & 50.4 \\
\hline 84 & Tanzania & 0.398 & 1,344 & 56 & 0.14 & 35 & 104 & 73 & 36 & 42.5 \\
\hline 85 & Thailand & 0.654 & 8,001 & 69 & 4.13 & 17 & 14 & 85 & 10 & 127.4 \\
\hline 86 & Tunisia & 0.683 & 7,979 & 74 & 2.29 & 5 & 21 & 82 & 7 & 63.5 \\
\hline 87 & Turkey & 0.679 & 13,359 & 72 & 3.91 & 5 & 22 & 93 & 17 & 92.1 \\
\hline 88 & Uganda & 0.422 & 1,224 & 53 & 0.09 & 15 & 135 & 56 & 35 & 132.9 \\
\hline 89 & Ukraine & 0.710 & 6,535 & 69 & 6.92 & 5 & 16 & 98 & 35 & 76.2 \\
\hline 90 & U. A. E. & 0.815 & 58,006 & 78 & 38.24 & 3 & 8 & 92 & 20 & 97 \\
\hline 91 & U.K. & 0.849 & 35,087 & 80 & 8.69 & 3 & 6 & 100 & 14 & 248.9 \\
\hline 92 & U.S.A. & 0.902 & 47,094 & 79 & 18.74 & 3 & 8 & 100 & 12 & 31.6 \\
\hline 93 & Uruguay & 0.765 & 13,808 & 76 & 1.76 & 5 & 14 & 98 & 27 & 19.7 \\
\hline 94 & Uzbekistan & 0.617 & 3,085 & 68 & 4.17 & 13 & 38 & 89 & 26 & 63.2 \\
\hline 95 & Venezuela & 0.696 & 11,846 & 74 & 5.65 & 12 & 18 & 83 & 38 & 29.0 \\
\hline 96 & Vietnam & 0.572 & 2,995 & 75 & 1.28 & 13 & 14 & 73 & 11 & 261.3 \\
\hline 97 & Yemen & 0.439 & 2,387 & 63 & 0.98 & 32 & 69 & 69 & 45 & 43.6 \\
\hline 98 & Zambia & 0.395 & 1,358 & 46 & 0.23 & 45 & 148 & 55 & 86 & 15.5 \\
\hline 99 & Zimbabwe & 0.140 & 176 & 45 & 0.79 & 39 & 96 & 83 & 80 & 31.7 \\
\hline
\end{tabular}

UNDP and World Bank statistical publications for Human Development Index (HDI), Gross National Income per capita (US\$ PPP), Life Expectancy, Child Mortality, Percentage of population living below poverty line, Percentage of population having access to safe water. Carbon dioxide emissions are obtained from data collected in year 2008 by Carbon Dioxide Information Analysis Centre (CDIA) for United Nations. Population density figures are obtained from United Nations and CIA World Factbook. 